\title{
Football Pollution: An Investigation of Spatial and Temporal Patterns of Crime In and Around Stadia in England
}

\author{
Justin Kurland $^{1}$, Nick Tilley ${ }^{2}$, and Shane D. Johnson ${ }^{2}$ \\ ${ }^{1}$ Institute for Security and Crime Science, University of Waikato, Hamilton, NZ \\ ${ }^{2}$ Department of Security and Crime Science, University College London, London, UK
}

\begin{abstract}
Inspired by theories of environmental criminology, this paper is concerned with the criminogenic potential of football matches. Do matches generate patterns of crime within grounds and beyond them? If so, over what period and over what distance are these effects produced? Police-recorded data for five football stadia for a six-year timeframe (2005 - 2010) are examined using non-parametric permutation tests. The spatial extent of any patterns are quantified and used to further examine differences in the temporal distribution of crime and incidents. Change in the spatial distribution of crime and incidents occurred around all five stadia and did so during those periods when the ambient population was elevated on match days. The results provide further support for theories of environmental criminology, suggesting that there is a higher risk of crime and incidents in the areas immediately around stadia during the hours that matches take place.
\end{abstract}

Keywords: Spatio-temporal crime patterns, football-related crime, Environmental criminology, policy, policing 


\section{Introduction}

For nearly a century there has been an on-going debate over who should pay for the policing of football matches (Shortt, 1924). In the United Kingdom, football clubs have sought ways to minimise their contributions. In several instances they have refused payment or initiated litigation on the assumption that they had not requested additional policing services for football matches (Home Affairs Committee, 2009). Indeed, most recently both the Greater Manchester Police and the West Yorkshire Police have been ensnarled in costly lawsuits concerning funding for policing matches at Wigan Athletic and Leeds United respectively (Home Affairs Committee, 2009; Leeds United Football Club v Chief Constable of West Yorkshire Police, 2014). Police forces have maintained that their role is to ensure public order and safety and therefore their services are required. Recent legal cases have revolved around who is financially responsible for policing areas surrounding grounds (Leeds United Football Club v Chief Constable of West Yorkshire Police, 2014).

In the UK, presently the 'footprint', the area for which football clubs are held responsible for the costs of policing, encompasses the stadium and land in the vicinity of the stadium that is owned by the club and/or where the police presence is for the benefit of the club and the purposes of the match (Smith, 2010). The current method for determining the geography over which clubs are held to account for the costs of policing is not evidence-based: it has little to do with the area over which, or places where football matches influence the likelihood of crime occurrence. The issue is, of course, contentious and the police believe that to maintain law and order, they must police an area larger than that suggested by numerous football clubs. To date, legal proceedings have placed the onus upon the police, who have often failed to demonstrate in the courts that patterns in crimes recorded by the police are influenced by football matches, and instead have relied primarily on anecdotal evidence to describe neighbourhood policing problems that football matches bring about.

This paper aims to assess the criminogenic effects of football matches at five different stadia by taking advantage of police-recorded crime and incident data for match days as well as a set of non-match comparison days. In the section that follows we provide further background on the history of football and crime, the criminological literature on stadia and other types of facilities, as well as the theoretical framework that guides the analyses that follow. Next, we provide details about the data, the analytic strategy that is adopted, and report our findings. Finally, we discuss the implications of the results for: (1) policy as it relates to the level of financial contribution (if any) football clubs should make towards the costs of policing football matches; (2) the allocation of police resources on match days for prevention and detection; and (3) for theories of environmental criminology.

\section{Football, Facilities and a Theoretical Framework}

Crime and football have long been bedfellows. Football-related disorder dates back to the Middle Ages when a folk version of the game was played in the UK (Elias and Dunning, 1971). Shortly after the Football Association was formed and the game was officially 
codified in 1863, organised professional football began to flourish and with it came stadia and supporters. Since these early days, police have frequently claimed that matches significantly increase crime levels in the area surrounding football grounds. In addition, a number of ecologically based approaches to studying crime (that focus on their pattern in time and space) suggest that facilities, such as football stadia, will often produce an increase in the number of offences in and around their grounds (Cohn and Breetzke, 2013; Kurland et al, 2014). For example, studying other types of facilities that affect the ambient population in their vicinity, Roncek and Lobosco (1983) report that high schools draw in large numbers of people. Moreover, these often include offenders who take advantage of serendipitous opportunities thereby leading to an increase in the number of offences that take place. Block and Block (2000) report similar results around train stations.

According to the routine activity approach a crime occurs when, in the course of normal activities, a motivated offender and a suitable target converge in time and space in the absence of a capable guardian (Cohen and Felson, 1979). A professional football match is an archetypal example where these conditions for crime can be expected. Games result in increased populations (some of whose members may be motivated offenders, targets and others capable guardians) in a specific location under conditions that are conducive to certain types of crime. Those conditions include, for example, increased anonymity for would be offenders in crowds and also a ready supply of suitable victims who are distracted and hence more vulnerable. Thus, it seems reasonable to conjecture that the convergence of large numbers of people at football matches will produce added opportunities for crime, thereby increasing the numbers of crimes when matches are played.

Crime pattern theory (Brantingham and Brantingham, 1981), like the routine activity approach, focuses on patterns of crime. However, this theory is concerned specifically with spatial patterns of crime, and differs from the routine activity approach in focusing on how the necessary elements of crime come to converge in time and space. The theory posits that offenders are more likely to offend in areas with which they are familiar; these areas are usually those that they frequent whilst going about legitimate activities (e.g., pubs, railway stations) and/or are located along the pathways that connect such places. In the context of football matches, supporters must travel to the ground, and many fans will converge at locations outside of the stadium that are routinely visited on match days. These include nearby public houses, fast food restaurants, and the key transportation nodes used by supporters as they travel to and from the football grounds. Activity at these locations provides additional opportunities for crime in the surrounding areas. This convergence is time-limited: people tend to arrive before a match begins and leave after it ends (or shortly before depending on the result). As such, if football matches do influence levels of crime, then we would expect various types of crime to increase during the hours leading up to matches, during the match and after its conclusion, but not at other times of the day or on days when football matches do not occur.

In accordance with these two theories of environmental criminology, an increase in violent crime might be expected as a result of the increased density of people and the provocations caused by rival supporters' interactions with each other (Rotten, et al, 1978; Branscombe and Wann, 1992, Gordon, 2004). At the same time, but with alternative precipitators, we would expect various forms of acquisitive crime, such as theft and 
handling, and criminal damage to increase because of a lack of supervision (Mustaine and Tewksbury, 1998; Engstad, 1975) and the increased stealth afforded by crowds. The increase in the prevalence of these types of crime event-where there is an expectation for more crime events on match days - will also likely result in a change in the temporal crime and incident patterns during these days. More generally, recent research suggests that busy places offer criminal opportunity and so one expectation in the current study is that crime at and around football stadia should increase on match days (Wilcox and Eck, 2011)

Kurland et al (2014) tested this hypothesis by comparing counts of crime around Wembley National Stadium on match, and on equivalent non-match days. In that study, the non-match days selected for comparison purposes were selected so as to be as similar as possible to the match days. For example, if a match took place on a Saturday, for the purposes of comparison the closest Saturday on which no football match occurred at Wembley stadium was selected as a comparator. Findings indicated that significantly more crimes occurred on match days up to 750 metres from the stadium than on relevant comparators. This approach to analysis may provide a meaningful way for identifying the area over which football clubs should be held responsible for the costs associated with policing matches. At present, the typical area for which clubs are held responsible includes the stadium itself and the immediate vicinity around the ground, to a distance of approximately 100 metres. If the findings of the earlier study are generalisable, this would suggest that the impact of football matches extends over a greater range than that for which clubs are currently expected to pay. Our first hypothesis thus focuses on this issue and can be summarised as follows: differences in the spatial pattern (and count) of incidents of crime and disorder are expected on match and non-match days, with more events expected on the former than the latter.

Analyses are also conducted to examine the distance over which differences exist both for crime in the aggregate and for specific types of crime (violence against the person, theft and handling, criminal damage; and other forms of crime). To compliment the spatial analyses, we examine whether the timing of crime events differs for match and non-match days, as expected. With respect to the policy issue discussed above this is important, as presently, clubs pay for the three hours prior to match kick off and the two hours after and it is unclear as to whether this is a sufficient period of time. Hypothesis 2 thus concerns the timing of events and can be expressed as follows: differences in the timing of incidents of crime and disorder are expected on match compared to non-match days, with more events expected before and after matches on match than non-match days. Again, analyses are conducted for all crimes considered and for particular types of crime to examine whether the patterns are consistent across offence types.

In the next section we summarise the data employed and the approach to analysis before presenting our findings. The findings are then discussed with respect to their implications for criminological theory and policy.

\section{Data and Methods}

This study used geocoded crime and incident data provided by the West Midlands Police, 
West Yorkshire Police, South Yorkshire Police, and British Transport Police for the five football clubs mentioned above. Crime and incident data are fundamentally different. Crime data clearly capture only crimes. Incident data, however, can be generated in a number of ways. They include, but are not limited to, emergency calls (or calls for service) about crimes in progress or concerns about disorder, not all of which lead to arrests. The data provided included 51,681 crimes and 159,363 incidents. A breakdown of these crimes and incidents by club is shown in Table 1. Building on previous work (Kurland et al, 2010), data were assembled for events that occurred within a threekilometre radius around each club for a six-year timeframe (2005 - 2010). This provides for a consistent estimation of how spatial and temporal patterns of crime and incidents differ on match and non-match days.

\section{Table 1 here}

Prior to analysis, the days on which matches took place at the selected stadia were identified. A Java-based program was then used to identify relevant comparison days to set against those on which matches were played. The methods used to select the sample of non-match days were designed to reduce the likelihood that confounding variables, such as seasonality (Hird and Ruparal, 2007) or day of the week (Boba, 2009), would invalidate any estimate of the effect that football matches may have on spatiotemporal patterns of crime. The program identifies the seven days before and the seven days after a given match selecting one optimal comparator date in each week. If no match occurs on either date, and if neither has already been selected as the comparison day for another match, the earlier date is selected as the comparator to leave sufficient comparison days for matches occurring at a later date. However, if both dates are unavailable due to the occurrence of a match, or because they have been previously selected as a comparator, then the program search parameters are expanded to fourteen days before and after the match or event, and if still no suitable comparator is identified then the parameters are expanded to twenty-one days and then to twenty-eight days. There was a spatial overlap between Sheffield United's and Sheffield Wednesday's study areas and because of this an additional parameter that accounted for the match schedule for an additional club was used for these two clubs. This method helped to rule out the possibility of selecting a comparison day when there was in fact a match at one stadium but not the other. All other aspects of non-match comparison day selection followed the same search criteria. Using this program, comparator days were identified for 90 per cent of all matches and over 70 per cent of those identified as optimal comparator days were within seven days of the match day (see Table 2). Those matches where no comparison date could be identified within the twenty-eight day timeframe were excluded from the analyses.

\section{Table 2 here}

Next, all crimes and incidents that took place on the identified days for the study areas were classified in two ways. First, crimes were identified by type according to Home Office classification codes and then placed into six separate categories: total incidents, total crime, theft and handling, violence against the person, criminal damage and an amalgamated 'other' category that was made up of all other Home Office 
offences, such as robbery, burglary, sexual offences, drugs, fraud and forgery and other notifiable offences. Although variations in recording practices can be problematic with police-recorded data, particularly when comparing areas in different forces, the introduction in April 2002 of the National Crime Recording Standard minimises such problems (Simmons et al, 2003). Moreover, any such variation would not affect the results for each club.

Secondly, all geocoded crimes and incidents were aggregated to spatial zones by type of day and stadium considered using the formula for Euclidean distance, as per Eq. 1.

$$
d_{i j k}=\sqrt{\left(x_{i j k}-x_{k}\right)^{2}+\left(y_{i j k}-y_{k}\right)^{2}}
$$

where, $i$ refers to the crime considered, $j$ refers to the type of day considered (match or comparison day), $k$ refers to the stadium considered, $x_{i j k}\left(y_{i j k}\right)$ refers to the $\mathrm{x}(\mathrm{y})-$ coordinate for the crime $i$ for type of day $j$ at stadium $k$.

To facilitate comparisons across stadia, crimes and incidents were assigned to concentric geographic zones according to the distance from the stadium at which they occurred. Different radii could be used to define the geographic zones. Here we use increments of $250 \mathrm{~m}$. To take an example, any crime that occurred within 250 metres of a stadium was assigned to the innermost zone $(0-250 \mathrm{~m})$. Those crimes and incidents that took place between 250 and 500 metres were assigned to the second zone, and so on through successive 250 metre increments up to three kilometres from the stadium centre. See Fig. 1 for an example of synthetic match and comparison day crime data that illustrates the method.

\section{Figure 1 here}

The assignment of crimes and incidents to zones resulted in 12 groups of crime counts that were classified by their distance from the stadium for each type of day (match vs. non-match). Table 3 provides the count for both sets of days for each respective stadium across each of the 12, 250 metre zones.

\section{Table 3 here}

Allocating crimes to discrete zones also made it possible to calculate the spatial extent of the differences in crime patterns between match and non-match days. For example, the counts of crime from just zone one for match days could be compared against the same zone for non-match days. This could also be scaled up to compare larger areas around the stadia. For example, it was also possible to test the one kilometre area around the ground by comparing the sum of the crime counts in zones one to four on match days with the sum of the crimes in the same zones on comparison days. Nonparametric permutation tests were used to examine whether the counts of crimes within these radiating zones were, in statistical terms, significantly higher on match than nonmatch days.

Permutation tests are used to compute the probability with which a particular outcome would be observed, assuming the null hypothesis-in this case, that there were no differences between match and non-match days-were true. Permutation tests are 
preferred because they are non-parametric and hence require satisfaction of fewer assumptions about the data to be analysed (e.g. that the data are normally distributed) than their parametric counterparts.

To conduct the analysis, for a given test statistic, the expected distribution is derived by enumerating all —or a large sample of — values of the test statistic derived under the null hypothesis. In this case, the null hypothesis is that there is no difference between match and comparison day crime counts. Thus, if the null hypothesis is true, any differences observed between the two samples should be similar to those obtained if we were to randomly shuffle the crime counts between the two sets of days (i.e. this would simulate the expected outcome if there were no systematic difference across the two sets of days). One shuffle of the data represents one realization of the null hypothesis, and a full permutation of all possible combinations produces a distribution for the test statistic. A full permutation is often too computationally intensive (or unnecessary) and so a Monte Carlo (MC) simulation is commonly used to sample from all possible permutations. Having derived an expected distribution for the test statistic (assuming the null hypothesis), it is easy to compute the probability of observing a value at least as large as that actually observed if the null hypothesis were true (see Good, 2000; North et al, 2002) by computing where, in a rank-ordered list of the values for the expected distribution, the observed value falls (See Eq. 2).

$$
p=\frac{r+1}{n+1}
$$

where, $r$ is the number of values for the permuted data that are at least as large as the observed value, and $n$ is the number of permutations used (in this case 999).

The permutation test was implemented in two ways. First, the expected difference for the total count of crimes between match and non-match days was estimated to compute the probability that the difference observed could have occurred on a chance basis. More specifically, for each pairwise comparison (e.g. match days versus nonmatch days), the sum of the differences in the counts of offences for the all match and comparison days for each respective zone is calculated, as per Eq. (3)

$$
D_{j}=\sum_{i=1}^{N} \text { Match }_{i j}-\text { Comparison }_{i j}
$$

where, $i$ refers to the crime type and $j$ refers to the zone the crime occurred in. $M a t c h_{i j}$ refers to the count for crime type $i$ in zone $j$ for all match days. Comparison $i j$ refers to the count for crime type $i$ in zone $j$ for all comparison days.

One assumption of the above approach is that the difference in the total observed crime counts for match and non-match days is roughly equivalent, and hence that what is observed in the aggregate will generally apply for each pair of match-to-non-match day comparisons. This may or may not be a reasonable assumption. In the extreme, it is possible that for a single match-to-non-match comparison there may be a huge difference in the crime event counts for the match day and its associated non-match comparison day (e.g. 200 vs 10 events). For the approach so far described, events are (uniformly) 
randomly allocated to match and non-match days and hence the combination described is unlikely to emerge on a chance basis. For this reason, a variation of the above test was used that was based on different assumptions. For each match-to-non-match comparison the difference in the observed counts in each respective zone was again calculated. However, this was then compared with what would be expected if the observed daily counts per zone were preserved but the type of day on which they occurred (match versus non-match) was random.

To examine this, for each pairwise comparison (e.g. match days versus non match days), the sum of the differences in the counts of offences for each match day and comparison day is calculated, as per Eq. (4)

$$
D_{j}=\sum_{i=1}^{N} \text { Match }_{i j k}-\text { Comparison }_{i j k}
$$

where, $i$ refers to the crime type, $j$ refers to the zone the crime occurred in, and $k$ refers to the match day considered. Match $_{i j k}$ refers to the count for crime type $i$ in zone $j$ on match day $k$. Comparison $_{i j k}$ refers to the count for crime type $i$ in zone $j$ on comparison day $k$.

Next, the expected distribution of $D_{j}$, assuming the null hypothesis is true is computed. One permutation of the data can be produced using a uniform random number generator $(u R N G)$ and the following approach:

$$
\text { Match }_{i j k e}=\left\{\begin{array}{c}
\text { Match }_{i j k e} \text { if } u R N G<0.5 \\
\text { Comparison }_{i j k e} \text { Otherwise }
\end{array}\right.
$$

where, Match $_{i j k e}$ refers to the expected count of crime type $i$ in zone $j$ on match day $k$ for permutation $e$.

Where the value of the match count is swapped with that for the comparison day, the count for the comparison day is likewise switched for that of the match day. Completing this exercise for each match-comparison day pairing provides one permutation of the data that may be used to compute one value of the expected distribution of $D_{j}$. This procedure was repeated 999 times and Eq. 2 was used again to determine the statistical significance of the observed $D_{j}$.

The two approaches answer different questions. The first answers the question 'in total were there more crimes on match days than non-match days'. The second concerns the question 'in general, is it the case that more crimes consistently occur on match days than on comparable non-match days'. By using both approaches the results are triangulated. This approach to testing data allows consistencies across models to be identified and leads to greater confidence in the meaning and precision of the findings. Because the results for both types of analysis are generally consistent, for simplicity we report only those results for the second test. A complete set of results is available upon request. 
In addition to estimating the probability that the observed difference in daily crime counts was due to chance, it is also possible to examine precisely when (during the day) differences were observed. To facilitate comparisons across stadia, crimes and incidents were assigned to discrete time periods according to when they occurred. Different temporal intervals could be used. Here we use six four-hour intervals: Midnight to 3am, $4 \mathrm{am}$ to $7 \mathrm{am}, 8 \mathrm{am}$ to $11 \mathrm{am}$, noon to $4 \mathrm{pm}, 5 \mathrm{pm}$ to $8 \mathrm{pm}$ and $9 \mathrm{pm}$ to midnight. Moreover, to avoid dilution effects, the analyses focus on events that occurred within the geographical areas within which differences were observed. Table 4 provides the counts of crime and disorder for each respective stadium for both types of day.

\section{Table 4 here}

As before, non-parametric permutation tests were used to estimate the probability of seeing a difference equal to or greater than that observed for the two types of day and for the six four-hour intervals considered.

\section{Results}

\section{Spatial Patterns}

In this section, we consider if and how the location of offences differed on match and non-match days. We focus on changes in the $3 \mathrm{~km}$ areas around the stadia to determine the distance over which differences in the counts of crime can be reasonably attributed to activity at the stadia.

As shown in Figure 2, which includes the aggregate count for all match (and comparison) days and the mean count per match (and comparison) day, for four of the five clubs included in the study, results suggest a significant increase in match day counts of offences and incidents around the stadia. Considering crime in the aggregate, significantly elevated counts of incidents of crime were observed up to around $1 \mathrm{~km}$ from the stadia for Aston Villa, Leeds United, and Sheffield Wednesday (ps $<0.001$ ). For example, across all match days considered, 1,079 crimes (mean 13.58 per match) occurred up to $1 \mathrm{~km}$ from Leeds United on match days compared to a total 485 (mean 10.24) on the non-match equivalents. For incidents, there were increased counts for all clubs; however there was considerable variation with respect to the spatial extent of this elevation in crime count. For Wolverhampton, the increase was observed over only a very limited distance $(250 \mathrm{~m})$ from the ground $(\mathrm{p}<0.001)$. For all other clubs there were elevated counts of incidents up to at least $500 \mathrm{~m}$ from their respective stadium centre (ps<0.05). This "spillover" is in line with the theories of environmental criminology discussed in the introduction, whereby an increased number of people in areas around stadia on match days is anticipated to provide more opportunities for crime.

Considering specific crime types, elevated counts of violent crimes were observed for Aston Villa, Leeds United, Sheffield United, and Sheffield Wednesday, though the spatial extent varied between $250 \mathrm{~m}$ and $1 \mathrm{~km}(\mathrm{ps}<0.01)$. For all clubs, relative to comparison days, there appeared to be elevated counts of theft and handling on match 
days, with increases at Aston Villa and Leeds United extending up to nearly $2 \mathrm{~km}$ from the ground (ps<0.01).

For criminal damage, the analysis revealed elevated counts of offences at Aston Villa, Leeds United, Sheffield United, and Sheffield Wednesday. For two study areas (Aston Villa and Sheffield Wednesday), the increase on match days appeared to extend to up to $2 \mathrm{~km}$ beyond the confines of the stadia (ps<0.01). Finally, Aston Villa, Leeds United and Sheffield Wednesday had elevated numbers of crimes in the amalgamated category 'other,' with an increase in the stadium and immediately outside the stadium for Leeds United $(\mathrm{p}<0.001)$ as well elevated counts in areas $500 \mathrm{~m}$ and $1 \mathrm{~km}$ from the grounds at Aston Villa and Sheffield Wednesday respectively (ps<0.01).

\section{INSERT FIGURE 2 HERE}

\section{Temporal Patterns}

In this section, we consider if and how the timing of offences differed on match and nonmatch days. We focus on changes in those areas around the stadia for which differences in the count of crime were reliably observed in the preceding analyses, since it is in these areas that changes in the timing of offences might reasonably be attributed to activity at the stadia. For example, for Aston Villa, changes in the temporal profile of offences were examined for up to the $1 \mathrm{~km}$ from the centre of the stadium. In the case of criminal damage, the analysis was extended to include offences that occurred up to $2.5 \mathrm{~km}$ from the centre of the stadium, as it was over this distance that differences were observed for this type of offence (see Figure 2).

To test whether there were statistically significant differences in the timing of offences on match and non-match days, a MC permutation test (described above) was used to compare hourly counts of crime for the two types of days. Results for all five clubs included in the study suggest a significantly greater number of incidents on match days as well as a higher average number of incidents. Figure 3, which includes aggregate counts for both sets of days as well as daily averages, indicates that for both incidents and crime, significant differences were commonly observed during the daytime, which is when matches are typically scheduled in the UK. More specifically, roughly 61 per cent of all match start times occur during the period between noon and 3pm, 35 per cent occur between $4 \mathrm{pm}$ and $7 \mathrm{pm}$, and 4 per cent take place between $8 \mathrm{pm}$ and midnight. To capture the club specific distribution of match kick offs, the total count and percentage of matches that occurred for each temporal period are included along the top of Figure 3.

In the case of incidents (calls for service), the results are striking, with a greater number of incidents at all clubs for the period between noon and $7 \mathrm{pm}$ (all ps <0.01). With the exception of Aston Villa, significant increases were also observed for the period $8 \mathrm{am}$ to noon at all clubs (all ps<0.01), which is the period immediately before many matches are typically scheduled to commence. Significant increases were also observed between 8pm and midnight at three clubs (Leeds United, Sheffield Wednesday and Wolverhampton), between midnight and 3am at Sheffield Wednesday's ground, and at 
two clubs (Leeds United and Wolverhampton) there were more incidents than usual between $4 \mathrm{am}$ and $8 \mathrm{am}$.

Considering crime in the aggregate, with the exception of Wolverhampton, a significantly greater number of events occurred at all clubs for the period between noon and midnight (all ps<0.001). Significant increases in the number of violent offences occurred at Aston Villa and Leeds United between noon and midnight (ps<0.01) with the latter also experiencing a significant increase between midnight and $3 \mathrm{am}(\mathrm{p}<0.05)$. Significant increases in violent offences were also observed at Sheffield Wednesday between $4 \mathrm{pm}$ and midnight.

There were some variations in differences in the timing of theft and handling offences (ps<0.05) at Aston Villa, Leeds United, Sheffield United, and Sheffield Wednesday. However, increases tended to occur between noon and $7 \mathrm{pm}$ - the period when nearly all scheduled football matches take place. An increased number of criminal damage offences (ps $<0.01$ ) occurred at both Aston Villa and Leeds United between noon and $3 \mathrm{pm}$ as well as between 8pm and midnight. Finally, Aston Villa, Leeds United, and Sheffield Wednesday all had significantly elevated counts (ps<0.05) of crimes in the amalgamated category 'other,' with an increase between noon and midnight.

\section{Conclusion}

Informed by theories of environmental criminology, the aim of this study was to examine if and how the occurrence of crime and disorder are affected by activity at football stadia on match days. Relative to similar non-match days, the results suggest that crime and disorder do increase at and around most clubs, and that such changes are observed for most of the offence types considered here. Rather than being limited to the immediate vicinity of the football grounds, it is also clear that problems spill over to areas up to a distance of $2.5 \mathrm{~km}$ away. This effect exceeds what would be expected on the basis of chance and was observed in all study locations for disorder and in four of the five study locations for crime. The results also show that these elevated counts of crimes consistently occur during the few hours leading up to matches, during matches and following their conclusion. They are also observed at other times of the day but not so consistently. Such findings provide more solid evidence (rather than anecdote) for use by either clubs or police services in making their cases as to the level of financial contribution football clubs should make towards the costs of policing football matches, assuming that it is right that they be asked to make any contribution.

This research has also shown how evidence can be collected and analysed to work out where and when supplementary policing is most needed, possibly enabling savings in overall costs to be made. The methodology provides a robust evidence-based approach to estimating the effects observed at individual football grounds that may help direct efforts at the prevention and detection of crime.

The methodology used in this study could be adopted in relation to other facilities that may generate crime, where there may be court proceedings over who should bear the costs of any supplementary policing that may be required. Major entertainment events 
and non-football sports occasions in large venues, for example, could be subjected to similar analyses. The possibility of litigation over payment for policing these, as well as football matches, highlights the potential for and importance of court access to systematic, empirical evidence.

The findings also provide further support for theories of environmental criminology, such as routine activity and crime pattern theory. These predict an increased risk of crime before, during, and after matches since it is during these periods that there will be a growth in the ambient population in and around football stadia. A number of potential contributors to these crime patterns are worth considering. For example, the elevated number of offences may be a function of extended hours of alcohol consumption and/or of the darkness (Tompson and Bowers, 2013) associated with later match kick offs, which provides greater anonymity to offenders. But, almost certainly the raised crime levels on match days reflect the larger number of potential opportunities that become available when supporters flood areas around the grounds.

There are some possible rival explanations that may account for differences in match versus non-match comparison day crime counts, which cannot conclusively be ruled out and should be considered in future research. For instance, one possible reason for larger crime counts on match days might be the additional police officers deployed in and around stadia, whose attention is drawn to incidents of crime and disorder. This could go some way to explaining what is recorded inside stadia and directly outside them. However, this is unlikely to explain the differences observed at distances beyond those where additional policing resources are allocated on match days. Another possibility could be that those who attend football matches are more likely to commit offences. Credence for this potential explanation can be found in studies of football hooliganism that have frequently identified consistency between the socio-demographic profile of those who attend matches and the profile of those most likely to be involved in violent crime more generally in the UK (Taylor 1976; Clarke 1978; Marsh 1988; Dunning Maguire, Murphy, and Williams 1982; Guilianotti 1994). That is, they are relatively young white men with working class backgrounds (Frosdick and Marsh 2005). This may offer a partial explanation for increases in violent crime, but the literature on hooliganism offers little insight beyond these simple demographic factors that would help explain increases in acquisitive crime such as theft and handling and criminal damage.

Lastly, the findings suggest that the current method of charging football clubs in the UK based on the geographic extent of their property does not fully account for the true impact of football on crime in the area around these grounds. Indeed, the current findings provide empirical evidence that football matches significantly increase crime and disorder in areas that extend beyond the roughly $100 \mathrm{~m}$ radius for which football clubs currently subsidize the police. Further research would be needed to determine if such results apply to all stadia, but given the diversity of the grounds considered, the current study goes some way towards establishing the external validity of the findings presented. This complements the anecdotal evidence previously presented in court, which has proven insufficient. Thus, such scientific methods may assist jurors and judges by providing unbiased estimates of the effect that football matches have on the 
neighbourhoods they are nested within to help to more fairly compensate match day policing services. 


\section{References}

Block, R.L. and Block C.R. (2000) Analyzing Crime Patterns: Frontiers in Practice. In: J.H. Mollenkopf (ed.) Analyzing crime patterns: Frontiers of Practice. London: Sage, pp. 137-152.

Santos, R.B. (2009) Crime Analysis With Crime Mapping 2nd ed. Thousand Oaks: Sage. Branscombe, N.R. and Wann, D.L. (1992) Role of Identification with a Group, Arousal, Categorization Processes, and Self-Esteem in Sports Spectator Aggression. Human Relations 45(10): 1013-1033.

Brantingham, P.L. and Brantingham, P.J. (1981) Notes on the geometry of crime. In: P.J. Brantingham and P.L. Brantingham (eds.) Environmental Criminology. Illinois: Waveland Press, pp. 27-54.

Clarke, J. (1978) Football and working class fans: tradition and change. In: R. Ingham (ed.) Football Hooliganism: The Wider Context. London: Inter-action Imprint, pp. 37-60.

Cohen, L.E. and Felson, M. (1979) Social Change and Crime Rate Trends: A Routine Activity Approach, American Sociological Review 44:588-605.

Breetzke, G. and Cohn, E. G. (2013) Sporting events and the spatial patterning of crime in South Africa: Local interpretations and international implications, Canadian Journal of Criminology and Criminal Justice 55(3): 387-420.

Dunning, E., Maguire, J., Murphy, P., and Williams, J., (1982) The social roots of football hooliganism, Leisure Studies 39: 458-78.

Elias, N. and Dunning, E. (1971) The Sociology of Sport: A Selection of Readings. London: Frank Cass.

Engstad, P.A. (1975) Environmental Opportunities and the Ecology of Crime. In Silverman, R.A., Teevan, J.J. and Sacco, V.F. (eds.), Crime in Canadian Society. Toronto: Butterworths, pp. 203-219.

Frosdick, S. and Marsh, P. Football Hooliganism. (2005) London: Willan.

Good, P.I. (2000) Analyzing the Large Number of Variables in Biomedical and Satellite Imagery. Hoboken: John Wiley \& Sons, Inc.

Guilianotti, R. (1994) Social identity and public order: political and academic discourses on football violence, In: R. Giulianotti et al. (eds) Football, Violence and Social Identity. London: Routledge, pp. 9-37.

Hird, C. and Ruparel, C. (2007) Seasonality in recorded crime. London, UK: Home Office, Technical Report no. 02/07.

House of Commons, Home Affairs Committee (2009) The Cost of Policing Football Matches. London, UK. Tenth Report of Session 2008-09.

Kurland, J., Johnson, S.D. and Tilley, N. (2010) Late weekend kick-offs at premier football matches and their possible link to increased levels of alcohol-related ASB and disorder. London, UK. Government Office for London.

Kurland, J., Johnson, S. D. and Tilley, N. (2014) Offenses around Stadiums: A Natural Experiment on Crime Attraction and Generation, Journal of Research in Crime and Delinquency. 51(1): 5-28.

Leeds United Football Club v Chief Constable of West Yorkshire Police (2014) 1 QB 168.

Marsh, P. (1988) Tribes. London: Pyramid. 
Mustaine, E.E. and Tewksbury, R. (1998) Predicting Risks of Larceny Theft Victimization: A Routine Activity Analysis Using Refined Lifestyle Measures. Criminology 36: 829-858.

North, B., Curtis, D. and Sham, P. (2002) A note on the calculation of empirical P values from Monte Carlo procedures. American Journal of Human Genetics 71: 439.

Roncek, D.W. and Lobosco, A. (1983) The Effects of High Schools on Crime in Their Neighborhoods. Social Science Quarterly 64: 598-613.

Rotten, J., Olszewski, D., Charleton, M. and Soler, E. (1978) Loud speech, conglomerate noise and behavioural after effects. Journal of Applied Psychology 63: 360-365.

Russell, G.W. (2004) Sport Riots: A Social-Psychological Review. Aggression and Violent Behavior 9: 353-378.

Shortt, E. (1924) Report of the departmental Committee on crowds. London, UK: Home Office. Crowds Committee, Stationery Off.

Simmons, J., Legg, C. and Hosking, R. (2003) National Crime Recording Standard (NCRS): An analysis of the impact on recorded crime Companion Volume to Crime in England and Wales 2002/2003. London, UK: Home Office. Report 32/03.

Smith, D. (2010) Guidance for Football Deployment and Cost Recovery, Association of Chief Police Officers of England, Wales and Northern Ireland. London, UK.

Taylor, I. (1976) Spectator violence around football: the rise and fall of the "working class weekend. Research Papers in Physical Education 4: 4-9.

Tompson, L. and Bowers, K., 2013. A stab in the dark? A research note on temporal patterns of street robbery. Journal of Research in Crime and Delinquency 50(4): 616631.

Wilcox, P. and Eck, J.E. (2011) Criminology of the unpopular: Implications for policy aimed at payday lending facilities. Criminology and Public Policy 10(2): 473482. 
Table 1: Crimes and incidents within a three-kilometre radius at each club over six years Football Club Crimes Incidents

Aston Villa $\quad 8,279 \quad 33,960$

Leeds $\quad 15,653 \quad 38,226$

Sheffield Utd $\quad 12,399 \quad 39,415$

Sheffield Wed $\quad 5,775 \quad 20,294$

Wolverhampton $\quad 9,575 \quad 27,468$

Total $\quad 51,681 \quad 159,363$


Table 2: Summary of match and non-match day samples

\begin{tabular}{lcccccc} 
Football Clubs & $\begin{array}{c}\text { Total Match } \\
\text { Days }\end{array}$ & 7 Day & 14 Day & 21 Day & 28 Day & $\begin{array}{c}\text { Total } \\
\text { Comparison Day }\end{array}$ \\
\hline Aston Villa & 116 & 77 & 14 & 8 & 5 & 104 \\
Leeds & 138 & 125 & 10 & 3 & 0 & 138 \\
Sheffield Utd & 127 & 65 & 12 & 10 & 14 & 101 \\
Sheffield Wed & 126 & 63 & 14 & 13 & 8 & 98 \\
Wolverhampton & 124 & 122 & 2 & 0 & 0 & 124 \\
\hline Total & 631 & 452 & 52 & 34 & 27 & 565
\end{tabular}


Table 3: Total match and comparison day () incident, crime, and crime category counts for each respective zone and study area

\begin{tabular}{|c|c|c|c|c|c|c|c|c|c|c|c|c|}
\hline Club & $0-250$ & $251-500$ & $501-750$ & $751-1000$ & $1000-1250$ & $1250-1500$ & $1500-1750$ & $1750-2000$ & $2000-2250$ & $2250-2500$ & $2500-1750$ & $2750-3000$ \\
\hline Aston Villa & $13(83)$ & $446(360)$ & $845(730)$ & $665(659)$ & 848 (729) & 1304 (1237) & $1443(1440)$ & $1712(1751)$ & $1684(1732)$ & $2040(2062)$ & $2178(2282)$ & $3559(3688)$ \\
\hline Leeds & $60)$ & 3) & (469) & 7) & $1447(1$ & 0) & 1941 & (1249) & 1496 & 34) & 2753 & 421 \\
\hline d Utd & $11(220)$ & 861 (774) & 1171 (1135) & $1728(1567)$ & $2543(2403)$ & 2063 (1977) & 2032 (1975) & 1799 (1666) & $1918(1811)$ & $2006(1861)$ & 1836 (1797) & $2040(1821)$ \\
\hline Sheffield Wed & $261(101)$ & 343 (234) & $394(402)$ & $770(667)$ & 927 (842) & $898(881)$ & 891 (837) & 1193 (1117) & 985 (869) & $856(943)$ & 1424 (1299) & $1596(1564)$ \\
\hline Wolverhampton & 368 (178) & $1292(1208)$ & 2384 (2281) & $2616(2501)$ & $1542(1571)$ & $1520(1605)$ & 1667 (1678) & 1417 (1391) & 1313 (1357) & 1588 (1582) & 1416 (1446) & $1717(1800)$ \\
\hline Aston Villa & $129(17)$ & $181(98)$ & $276(153)$ & $194(115)$ & $228(203)$ & $333(281)$ & $451(413)$ & $423(433)$ & $444(371)$ & $467(478)$ & $522(549)$ & $716(804)$ \\
\hline Leeds & $364(22)$ & $86(44)$ & $272(147)$ & 357 (272) & 491 (449) & $586(595)$ & $672(611)$ & $410(428)$ & $545(558)$ & 951 (949) & $1266(1263)$ & $2172(2143)$ \\
\hline ffield Utd & 236 (104) & $268(225)$ & $504(457)$ & $662(665)$ & 935 (893) & $751(736)$ & $554(524)$ & 435 (475) & $552(538)$ & 439 (446) & $444(505)$ & $528(523)$ \\
\hline & $96(31)$ & $121(65)$ & $120(88)$ & $294(210)$ & $327(280)$ & $320(258)$ & $212(216)$ & $313(295)$ & $271(236)$ & $223(251)$ & $337(330)$ & $463(418)$ \\
\hline Wolve & $43(33)$ & 0) & 3) & 599 & 2) & 1) & 387 (349) & $343(318)$ & 345 (302) & 10) & 378 & 439) \\
\hline Aston Villa & (10) & 0 & 9) & 5 & $38(46)$ & $86(94)$ & 100 & 121 & 106 & 129 & 146 & 225) \\
\hline Leeds & $232(3)$ & $29(5)$ & $35(23)$ & $69(45)$ & (89) & $113(136)$ & $121(129)$ & $70(80)$ & $62(79)$ & $148(126)$ & $250(226)$ & $326(341)$ \\
\hline & $90(13)$ & $33(30)$ & 124 (113) & $136(110)$ & $265(251)$ & $106(90)$ & $89(79)$ & $79(65)$ & $75(64)$ & $79(52)$ & $60(64)$ & $66(56)$ \\
\hline Sheffield Wed & $37(6)$ & $24(7)$ & $20(18)$ & $74(42)$ & $52(53)$ & $57(44)$ & $48(48)$ & $47(51)$ & $52(53)$ & $32(44)$ & 77 (69) & $72(62)$ \\
\hline Wolverhampton & $13(10)$ & $100(86)$ & 202 (203) & $154(121)$ & $84(80)$ & $85(93)$ & $104(79)$ & $83(72)$ & $78(59)$ & $86(80)$ & $99(78)$ & $100(92)$ \\
\hline Aston Villa & 2 & (29) & 1 & 3) & $63(42)$ & $112(63)$ & 1 & $106(126)$ & $101(91)$ & $101(123)$ & 9) & 6) \\
\hline Leeds & $54(6)$ & 10) & 3) & 0) & 1 & 1 & 5) & 6) & 1) & 6) & 6) & $1237(1178)$ \\
\hline Sheffield Utd & $80(44)$ & $125(95)$ & 232 (199) & $282(250)$ & $424(393)$ & 395 (394) & $226(207)$ & $172(184)$ & $210(204)$ & $146(156)$ & $143(167)$ & $196(205)$ \\
\hline Sheffield Wed & $43(12)$ & $43(22)$ & $61(35)$ & $97(89)$ & $126(100)$ & (1) & $11(00)$ & $102(84)$ & $76(69)$ & 17 & & $163(166)$ \\
\hline Wolverhampton & $17(7)$ & $119(128)$ & $366(293)$ & $217(212)$ & $98(125)$ & $90(121)$ & $92(83)$ & $83(91)$ & $85(84$ & 109 & $95(94)$ & $141(107)$ \\
\hline Aston Villa & $6(2)$ & $29(23)$ & $65(28)$ & $37(27)$ & (36) & $56(43)$ & $60(45)$ & $77(68)$ & $96(54)$ & $96(69)$ & $95(92)$ & $102(124)$ \\
\hline Leeds & $26(7)$ & $21(10)$ & $58(32)$ & $79(63)$ & $117(114)$ & 163 (190) & $188(151)$ & $96(108)$ & $105(98)$ & 119 (112) & $168(152)$ & $200(225)$ \\
\hline Sheffield Utd & $25(12)$ & $45(24)$ & 9) & 6) & 3) & 9) & ) & ) & 3) & 4) & 12 & 143) \\
\hline Sheffield Wed & 5 & 5) & 6) & 5 & 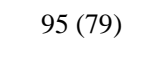 & 4) & 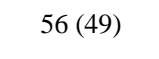 & $93(85)$ & $78(69)$ & $66(76)$ & $92(81)$ & 1) \\
\hline Wolverhampton & $5(5)$ & $1(32)$ & $1(32)$ & 0.677 & 10 & $69(76)$ & $53(6$ & 79 & $76(6$ & 00 & 74 & 01 \\
\hline Aston Villa & $29(3)$ & $51(26)$ & 7 (44) & $45(33)$ & $89(79)$ & $79(8$ & $97(110)$ & $119(132)$ & $141(119)$ & 141 (149) & $156(194)$ & $243(259)$ \\
\hline Leeds & $52(6)$ & $13(19)$ & $48(39)$ & $4(84)$ & $114(112)$ & $139(150)$ & $188(186)$ & $139(124)$ & $131(130)$ & $353(345)$ & $248(249)$ & 409 (399) \\
\hline field Utd & $41(35)$ & $65(76)$ & $88(86)$ & $166(219)$ & $145(156)$ & 141(133) & $143(144)$ & $91(148)$ & $118(147)$ & $95(114)$ & $118(146)$ & 129 (119) \\
\hline Sheffield Wed & $11(6)$ & $34(21)$ & $18(9)$ & $56(32)$ & $54(48)$ & $65(57)$ & $31(39)$ & $71(65)$ & $65(45)$ & $44(67)$ & $80(85)$ & $92(89)$ \\
\hline Wolverhampton & $8(11)$ & $103(94)$ & 195 (94) & $159(148)$ & $134(129)$ & $122(121)$ & $128(126)$ & $105(87)$ & $106(91)$ & $123(146)$ & $110(108)$ & $163(136)$ \\
\hline
\end{tabular}


Table 4: Match and comparison day () incident, crime, and crime category counts for the significant area by period and study area

\begin{tabular}{|c|c|c|c|c|c|c|}
\hline Club & $0-3$ & $4-7$ & $8-11$ & $12-15$ & $16-19$ & $20-23$ \\
\hline Aston Villa & $129(110)$ & $95(64)$ & 163 (143) & 314 (238) & $426(294)$ & 318 (276) \\
\hline Leeds & $179(180)$ & $125(69)$ & 309 (177) & 315 (291) & $466(331)$ & 481 (366) \\
\hline Sheffield Utd & $141(121)$ & $98(86)$ & 134 (108) & $260(210)$ & $341(201)$ & $298(268)$ \\
\hline Sheffield Wed & $69(40)$ & $22(22)$ & $93(36)$ & $103(68)$ & $178(75)$ & 139 (94) \\
\hline Wolverhampton & $27(31)$ & $41(21)$ & $45(15)$ & $89(44)$ & $90(44)$ & $76(36)$ \\
\hline Aston Villa & $59(47)$ & $20(17)$ & $46(30)$ & $171(61)$ & 244 (115) & $220(93)$ \\
\hline Leeds & $68(79)$ & $28(23)$ & $46(46)$ & $259(84)$ & $340(121)$ & $338(132)$ \\
\hline Sheffield Utd & $44(45)$ & $21(20)$ & $32(32)$ & $101(56)$ & $161(84)$ & $145(92)$ \\
\hline Sheffield Wed & 168 (148) & $44(38)$ & $78(73)$ & 255 (139) & $326(240)$ & 407 (294) \\
\hline Wolverhampton & - & - & - & - & - & - \\
\hline Aston Villa & $10(0)$ & $1(2)$ & $1(3)$ & $16(5)$ & $55(12)$ & $35(8)$ \\
\hline Leeds & $11(6)$ & $4(4)$ & $10(7)$ & $98(9)$ & $118(24)$ & $124(26)$ \\
\hline Sheffield Utd & $3(2)$ & $2(1)$ & $3(0)$ & $17(2)$ & $39(3)$ & $26(5)$ \\
\hline Sheffield Wed & $3(1)$ & $2(1)$ & $3(3)$ & $9(1)$ & $27(1)$ & $17(6)$ \\
\hline Wolverhampton & - & - & - & - & - & - \\
\hline Aston Villa & $33(35)$ & $16(12)$ & $88(36)$ & $187(91)$ & $178(99)$ & 103 (77) \\
\hline Leeds & $83(81)$ & $23(22)$ & $68(69)$ & $193(80)$ & 314 (135) & $202(160)$ \\
\hline Sheffield Utd & $41(42)$ & $13(13)$ & $38(47)$ & $129(77)$ & $117(78)$ & $99(81)$ \\
\hline Sheffield Wed & $11(7)$ & $4(4)$ & $6(5)$ & $20(15)$ & $50(18)$ & $56(21)$ \\
\hline Wolverhampton & $1(1)$ & $0(0)$ & $2(3)$ & $4(1)$ & $10(2)$ & $0(0)$ \\
\hline Aston Villa & $44(48)$ & $30(25)$ & $36(35)$ & $130(76)$ & $88(83)$ & 232 (128) \\
\hline Leeds & $13(17)$ & $7(8)$ & $11(9)$ & $39(14)$ & $46(31)$ & $68(33)$ \\
\hline Sheffield Utd & $8(5)$ & $3(4)$ & $4(3)$ & $9(6)$ & $18(10)$ & $25(8)$ \\
\hline Sheffield Wed & $97(85)$ & $17(17)$ & $27(27)$ & $63(34)$ & $124(107)$ & 209 (170) \\
\hline Wolverhampton & - & - & - & - & - & - \\
\hline Aston Villa & $9(3)$ & $4(2)$ & $4(3)$ & $16(4)$ & $24(9)$ & $23(8)$ \\
\hline Leeds & $0(2)$ & $0(0)$ & $0(0)$ & $14(1)$ & $25(3)$ & $13(0)$ \\
\hline Sheffield Utd & - & - & - & - & - & - \\
\hline Sheffield Wed & $14(11)$ & $5(2)$ & $3(5)$ & $31(14)$ & $40(21)$ & $26(15)$ \\
\hline Wolverhampton & - & - & - & - & - & - \\
\hline
\end{tabular}


